\title{
ОЦЕНКА ЭФФЕКТИВНОСТИ МЕРОПРИЯТИЙ ПО СОВЕРШЕНСТВОВАНИЮ ИННОВАЦИОННОЙ ДЕЯТЕЛЬНОСТИ ОАО «РЖД»
}

\author{
(C) 2021 Пинчуков Алексей Владимирович \\ аспирант кафедры «Менеджмент качества» \\ Российский университет транспорта (МИИТ), Россия, Москва \\ E-mail:alx.pnchkv@gmail.com
}

(c) 2021 Гуськова Марина Федоровна

доктор экономических наук, профессор, профессор кафедры «Менеджмент качества»

Российский университет транспорта (МИИТ), Россия, Москва

E-mail: oet2004@yandex.ru

В статье рассмотрено влияние внешних факторов и внедренных инновационных процессов на эффективность инвестиционной деятельности ОАО «РЖД», необходимой для сохранения устойчивого развития компании. Проведен анализ эффективности программы «Внедрение современных технологий и использование инноваций» и «Бережливое производство», в соответствии с которым компания планирует сэкономить более 100 млрд. руб. (с учетом базы) до 2025 года.

Ключевые слова: транспорт, инновационная деятельность, эффективность

В условиях рыночной экономики, для увеличения своей конкурентоспособности, получения большей доли рынка и эффективного развития, компания должна вести активную инновационную деятельность.

В настоящее время по исследуемой проблематике накоплена определенная теоретическая и практическая научная база. Среди работ, в которых раскрываются различные аспекты анализа и совершенствования инновационной деятельности компаний можно выделить работы следующих авторов: Алетдинова А.А., Баранчеев, В. П., Медведев, В. П..

Холдинг ОАО «РЖД» разработал план повышения собственной эффективности на среднесрочную перспективу - «Сводная программа мероприятий по повышению операционной эффективности и оптимизации расходов ОАО «РЖД» на 2019-2025 гг.».

Как уже отмечалось, программа была разработана в 2018 году и скорректирована в соответствии с требованиями Правительства РФ. Пункты программы коррелируются с целями и задачами ДПР.

Главными целями программы являются:

1. достижение целей ДПР, посредством эффективного использования собственных ресурсов;

2. создание непрерывного процесса, позволяющий повысить эффективность компании.

Важно отметить, что в 2018 году компания
ОАО «РЖД» показала позитивный финансовый результат без участия государства. Осуществлен прирост следующего показателя - перевезенный груз. Этот показатель составил 1,9\%, или 1289,6 млн. т. Замечено улучшение структуры издержек и снижен рост себестоимости.

Для сохранения устойчивого развития компании и повышения эффективности необходимо учесть внешние факторы, необходимые для анализа развития компании.

Положительные показатели ОАО «РЖД»:

- улучшение качественных показателей работы;

- увеличение производительности парка локомотивов;

- уменьшения топливных и энергетических затрат.

При этом в сценарий заложен поступательный рост эффективности от проведенных мероприятий, который уже в прошлом году составил 29,4 млрд. руб., в 2020-м вырастет до 34,9 млрд. руб. и далее будет поступательно увеличиваться, составив 303,5 млрд. руб. за 7 лет.

Необходимо напомнить, что 45 млрд. рублей было инвестировано ОАО «РЖД» в 2018 г. в проект по повышению эффективности деятельности и уменьшению затрат.

Благодаря этому проекту, ОАО «РЖД» планирует достичь экономического эффекта в размере более 1 трлн. руб. в период с 2019 по 2025 года.

Говоря о структуре транспортных расходов 
Холдинга, которые необходимо оптимизировать, нужно отметить затраты на топливо и электроэнергию, составившие более 19\% в 2018 году.

Благодаря ввода в эксплуатацию ресурсосберегающих технологий, Холдинг планирует сэкономить более 20 млрд. руб. до 2025 года.

В первую очередь, а это около 85\% всех мероприятий направлены на снижение расходов на тягу.

Руководству ОАО «РЖД» предстоит решить ряд вопросов:

1. увеличение среднего веса поезда;

2. уменьшение порожнего пробега;

3. снижение времени простоя в ремонте;

Достичь поставленных целей, руководство ОАО РЖД планирует с помощью следующих мероприятий:

1. технологии движения поездов по твердым нитям энерго-оптимального графика;

2. сокращение издержек на работу маневровых локомотивов (сокращение парка и топлива). Это окажет положительное влияние на внедрение малых компрессорных установок для ремонта пути;

3. внедрение нового поколения тепловозов и электровозов с повышенной энергоэффективностью;

4. разработка широкого спектра технологий направленных на энергосбережение локомотивов путем организации электропитания от сети.
Необходимо добавить, что эффективное управление основными средствами - является одним из ключевых пунктов в программе по оптимизации издержек на локомотивном хозяйстве.

Здесь ставятся такие задачи:

1. привести количество техники к объему выполняемых работ;

2. уменьшение численности локомотивов, которые находятся в ремонте;

3. повысить коэффициент технической готовности локомотивов;

4. введение в эксплуатацию нового поколения локомотивов.

Благодаря выполнению вышеуказанных мероприятий, компания планирует получить дополнительные 78,4 млрд. руб. При этом, самыми эффективными мероприятиями в компании считают:

1. уменьшение числа локомотивов, требующих капитально ремонта (этого планируется достичь за счет введения нового поколения тепловозов с увеличенным межремонтным пробегом);

2. списание устаревших моделей локомотивов.

Стоит отметить, что изменение технологий ремонта пути значительно поможет сократить расходы компании. Новые рельсы будут иметь расширенную гарантию (1400 млн. т брутто) и

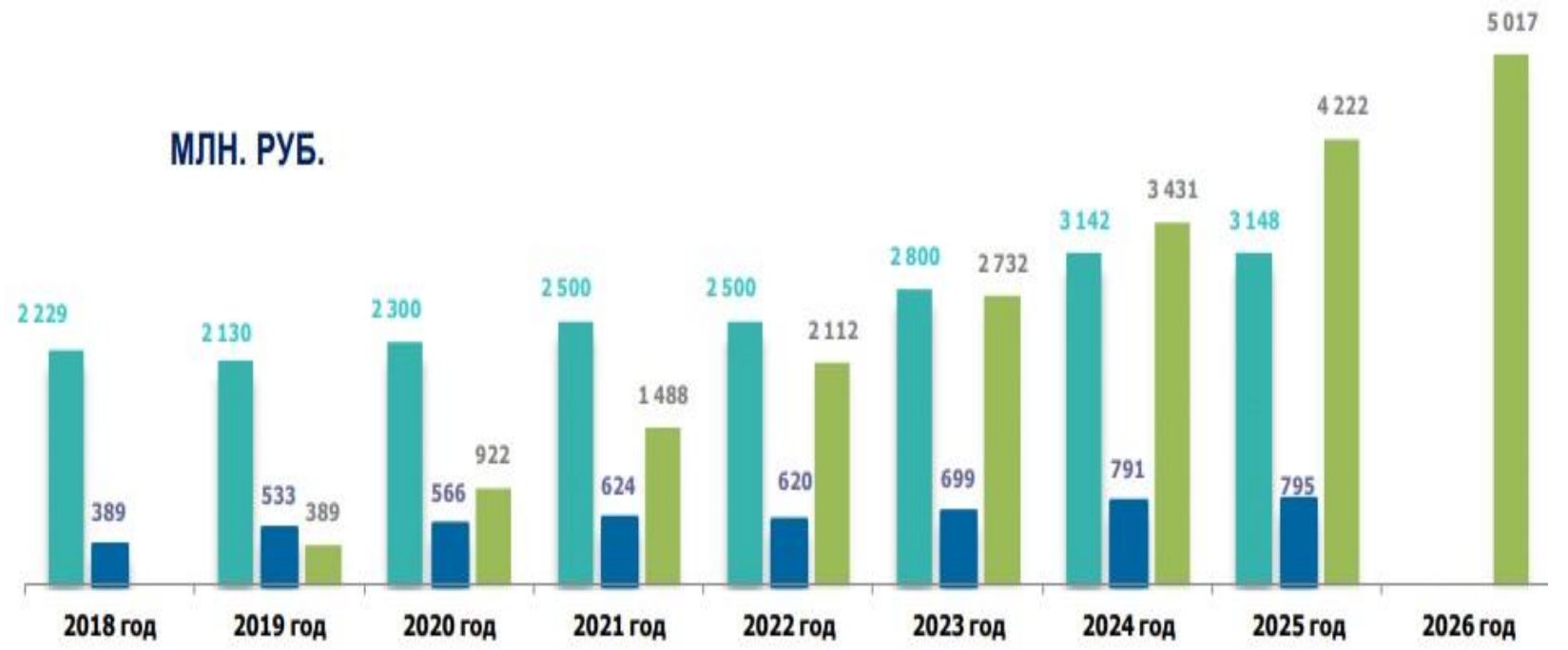

ШИНВЕСТИЦИОННЫЕ ЗАТРАТЫ 
позволят работать без замены на протяжении 4710 км пути следования. Это позволит привлечь дополнительные финансовые ресурсы в размере 34,8 млрд. руб.

Благодаря выполнению программы «Внедрение современных технологий и использование инноваций», компания планирует сэкономить 75,2 млрд. руб. (с учетом базы). Более того, благодаря программе «Бережливое производство» до 2025 года компания сможет достичь экономического эффекта в размере 47 млрд. руб. (с учетом базы).

K вышеперечисленному можно добавить следующие направление - «Повышение эффективности использования трудовых ресурсов». Суть этой программы состоит во внедрении безлюдных технологий:

- машинист сможет в одиночку управлять локомотивом, без помощи посторонних лиц;

- ввод в эксплуатацию технологических горок роспуска автоматического;

- уменьшение численности персонала в депо;

- передача работ на аутсорсинг.

Важнейшим показателем инновационного развития в ОАО «РЖД» является показатель «бережливое производство», основанное на том, что благодаря внедренным инновационным процессам в компании достигается определенный экономический эффект.

Далее на Рисунке 2 представлен экономический эффект от показателя «бережливое производство».

Таким образом, благодаря предлагаемым нами направлениям развития инновационной деятельности в ОАО «РЖД» совокупно будет достигнут экономический эффект по показателю «бережливое производство» в 1,592 млн. руб.

Что касается экономического эффекта, полученного в рамках мультифункциональных проектов, то он представлен далее на Рисунке 3.

Анализируя полученные данные, можно сказать, что доля экономического эффекта от мультифункциональных проектов характеризуется

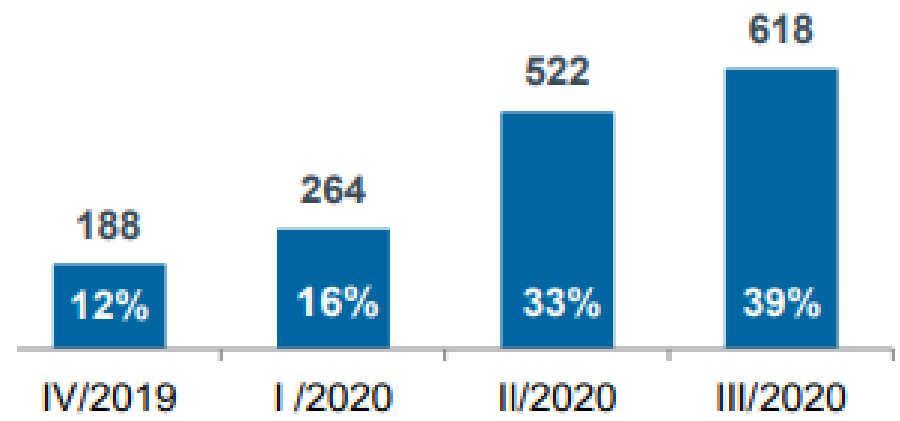

Puc. 2. Экономический эффект от показателя «бережливое производство» Источник: расчеты автора
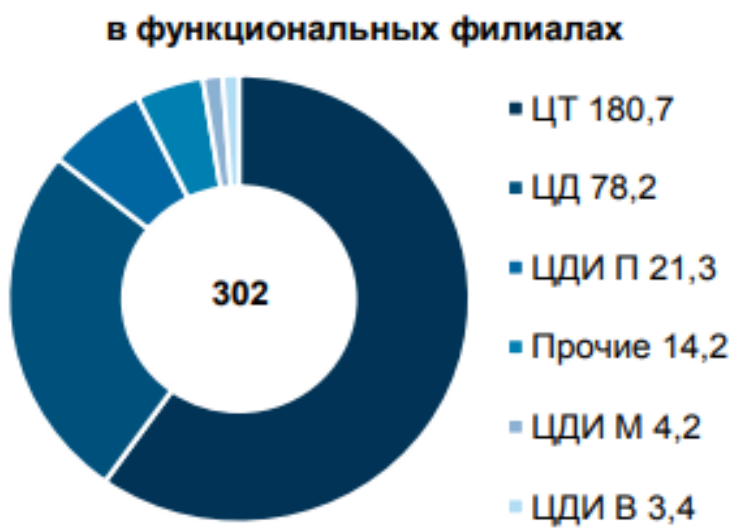

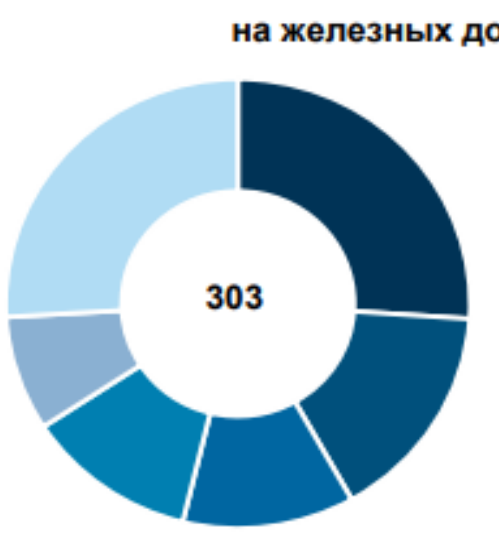

на железных дорогах

- OKT 78,9

- КБШ 47,7

- CEB 36,3

- ГОРЬК 36,2

В-СИБ 25

- Прочие 78,5

Puc. 3. Экономический эффект от показателя «бережливое производство» в разрезе мультифункциональных проектов ОАО «РЖД», млн. руб. Источник: расчеты автора 
18\% относительно общего эффекта.

Стоит также заметить, что доля экономического эффекта от мультифункциональных проектов была снижена на $4 \%$, что было связано с увеличением общего эффекта от инновационных проектов в контексте бережливого производства.

Все целевые показатели проводимых мероприятий будут ежегодно корректироваться и анализироваться. А именно, передаются на рассмотрение совета директоров Холдинга, где анализируются данные следующих ключевых показателей операционной эффективности:

- ключевые точки программ по повышению эффективности;

- показатель средней участковой скорости движения поезда;

- средний вес поезда;

- среднесуточная производительность ло- комотива;

- удельный расход электроэнергии и дизтоплива на тягу поездов;

- себестоимость перевозок;

- темп роста производительности труда.

Важно отметить, что при анализе достаточно ярко выделяется тот факт, что ее разработчики не учитывают возможный эффект для общего финансового результата компании, который по смыслу должен отражать результат оптимизации.

Также важно обратить внимание на тот факт, что большинство направлений и мер оптимизации работы направлены именно на хозяйство тяги, хотя максимальных эффектов ждут от Центральной дирекции инфраструктуры.

Программы подобного типа в обязательном порядке следует рассматривать комплексно, с учетом долгосрочного влияния на экономику.

\section{Библиографический список}

1. Алетдинова А.А. Методика формирования инновационного потенциала организации/А.А. Алетдинова // Вопросы инновационной экономики. - 2018. - № 1.- С. 13-18

2. Гетманцев А.А., Сомина И. В. Теория нечетких множеств как математический аппарат для оценки инновационного потенциала предприятия/А.А. Гетманцев, И.В. Сомина // Современные проблемы науки и образования. - 2018. - № 5. - С. 1-7

3. Стерликов Ф.Ф., Гуськова М. Ф., Стерликов П.Ф. Экономическая теория ценности как синтез теории полезности и теории стоимости

4. Вестник экономической интеграции. 2007. № 4. С. 47-60.Морозов А. В. Прогнозирование, проектирование и моделирование/А.В. Морозов.- Москва: КГТУ, 2017.-252 с.

5. Хозяйственные системы инновационного типа: теория, методология, 2 практика: монография / под ред. А.Н. Фоломьева.- М.: Экономика, 2011.-397 с.

6. Шумпетер Й.А. Теория экономического развития/Й.А. Шумпетер. Москва: Прогресс, 1982. Директмедиа Паблишинг Москва 2008. -583 с.

7. Экономическое обоснование инженерных проектов в инновационной экономике: учеб. пособие / под ред. М. Н. Корсакова, И. К. Шевченко.- Москва: ИНФРА-М, 2012.-144 с.

8. Harvard Business Review on Mergers and Acquisitions. - Harvard Business Press, 2018. - $172 \mathrm{p}$.

9. Rosenbaum, J.Investment Banking: Valuation, Leveraged Buyouts, and Mergers and Acquisitions.- Wiley; 9 edition, 2019. $-464 \mathrm{p}$.

10. Scott, C. Whitaker. Mergers \& Acquisitions Integration Handbook, + Website: Helping Companies Realize The Full Value of Acquisitions. - Wiley; 8 edition, 2018. - 192 p.

11. Официальный сайт ОАО «РЖД».- Москва.- Обновляется в течение суток.- URL: https://company.rzd.ru/ ru/9377 (Дата обращения: 18.03.2020). - Текст: электронный.

12. Информационный ресурс СПАРК.- Москва.-Обновляется в течение суток.-URL: http://www.sparkinterfax. ru (Дата обращения: 10.04.2020).- Текст: электронный.

13. Официальный сайт компьютерной справочной правовой системы Российской Федерации КонсультантПлюс.- Москва.- Обновляется в течение суток.- URL: http://www.consultant.ru (Дата обращения: 10.04.2020).- Текст: электронный.

14. Официальный сайт стандартов ИCO. - Москва. - Обновляется в течение суток.- URL: http://www.icc-iso.ru (Дата обращения: 10.04.2020).- Текст: электронный.

15. Официальный сайт Федеральной службы государственной статистики.- Москва.- Обновляется в течение cyтoк. - URL: http://www.gks.ru (Дата обращения: 10.04.2020).- Текст: электронный. 
16. Официальный сайт отчета Global innovation index.- Москва.- Обновляется в течение cyток.-URL: https:// www.globalinnovationindex.org/gii-2018-report (Дата обращения: 10.04.2020). - Текст: электронный.

17. Международный железнодорожный салон техники и технологий «PRO//Движение.Экспо.- Москва.- Обновляется в течение суток._URL: railwayforum.ru (Дата обращения: 10.04.2020).- Текст: электронный. 